\title{
The ABCs of autologous blood collection for ex vivo organ preservation
}

\author{
John R. Spratt, MD, MA, ${ }^{a}$ Lars M. Mattison, BS,,${ }^{\mathrm{a}, \mathrm{b}}$ Paul A. Iaizzo, PhD, ${ }^{\mathrm{a}, \mathrm{b}}$ and Gabriel Loor, MD, ${ }^{\mathrm{c}}$
} Minneapolis, Minn, and Houston, Tex

\footnotetext{
From the Departments of a Surgery and ${ }^{\mathrm{b}}$ Biomedical Engineering, University of Minnesota, Minneapolis, Minn; and the ${ }^{\mathrm{c}}$ Division of Cardiothoracic Transplantation and Circulatory Support, Michael E. DeBakey Department of Surgery, Baylor St Luke's Medical Center, Houston, Tex.

Disclosures: G.L. receives grant support from TransMedics, Inc (Andover, Mass) for involvement in 2 international trials, INSPIRE and EXPAND. The laboratory receives disposable replacement parts (non-clinical grade materials) for the animal OCS platform. All other authors have nothing to disclose with regard to commercial support.

Received for publication April 13, 2017; revisions received July 16, 2017; accepted for publication Aug 11, 2017; available ahead of print Nov 9, 2017

Address for reprints: Gabriel Loor, MD, Division of Cardiothoracic Surgery, Baylor St Luke's Medical Center, 6770 Bertner Ave, Suite C355, Houston, TX 77030 (E-mail: gabriel.loor@bcm.edu).

J Thorac Cardiovasc Surg 2018;155:433-5

$0022-5223 / \$ 36.00$

Copyright (c) 2017 by The American Association for Thoracic Surgery

http://dx.doi.org/10.1016/j.jtcvs.2017.08.036
}

Video clip is available online.

For decades, the supply of solid organs for transplant has remained relatively fixed, despite increasing demand. Ex vivo organ preservation (EVOP) allows prolonged preservation and extracorporeal evaluation of donor organs. Some EVOP platforms make use of acellular or packed red blood cell-based perfusates while others routinely utilize autologous donor whole blood (ADWB). ${ }^{1-3}$ In our laboratory experience with lung preservation, the use of ADWB is critical for prolonged ( $>12$ hours $)$ normothermic preservation and for the acutely injured lung; acellular perfusates or packed red blood cells do not allow meaningful recovery in swine models.,

Large-volume ADWB collection in the laboratory is straightforward, but it becomes complex in a clinical setting because of the demands of multivisceral procurement. As EVOP technologies proliferate, ADWB collection for organ preservation will become more common. We propose a standardized methodology for ADWB collection that is based on our accumulated experimental ( $>50$ swine) and clinical (5 brain-dead donors) experience.

\section{TECHNIQUE}

\section{Preoperative Considerations}

All on-site procurement, anesthesia, and organ procurement organization personnel should be apprised of planned ADWB collection. The sterile blood-collection system should be passed onto the field, and its components and use described to applicable staff. Protocols regarding bronchoscopy, blood gas collection, and communication with

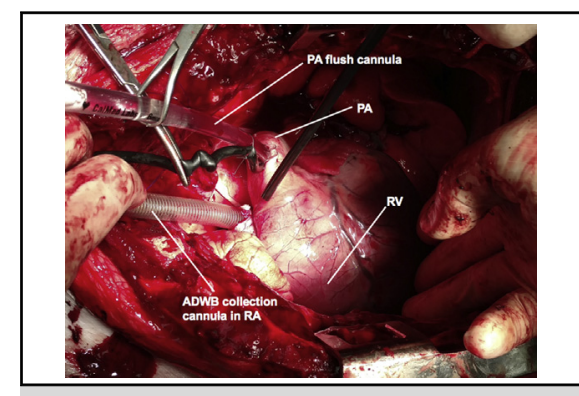

Right atrial cannulation for collection of autologous donor whole blood (ADWB).

\section{Central Message}

The collection of autologous donor whole blood for ex vivo organ preservation may be performed reproducibly in the setting of clinical organ procurement.

See Editorial Commentary page 436.

TABLE 1. Autologous donor whole blood collection

\begin{tabular}{l} 
Necessary supplies (in addition to standard setup for thoracic organ \\
procurement) \\
- Right atrial cannulation stitch \\
$\circ 3-0$ or 4-0 polypropylene or braided polyester per surgeon \\
preference \\
- Blood-collection system \\
○ 32F-40F straight venous cannula \\
○ Drainage tubing \\
○ 2-L blood-collection bag \\
○ Prepackaged collection system containing the above (eg, \\
TransMedics) may be used \\
Operative steps \\
1. Standard median sternotomy and inspection of thoracic organs \\
2. Judicious volume administration as appropriate \\
3. Full heparinization in coordination with abdominal team \\
4. Standard placement of aortic root and pulmonary artery flush \\
cannulas \\
5. RA purse-string placement and cannulation (collection system \\
clamping) \\
6. Trendelenburg positioning \\
7. Collection system unclamping \\
8. Collection of 1.5-2 L ADWB by gravity drainage \\
9. Collection system clamping and RA decannulation \\
10. Aortic crossclamping, antegrade flush, standard procurement \\
\hline
\end{tabular}

$R A$, Right atrial; $A D W B$, autologous donor whole blood. 

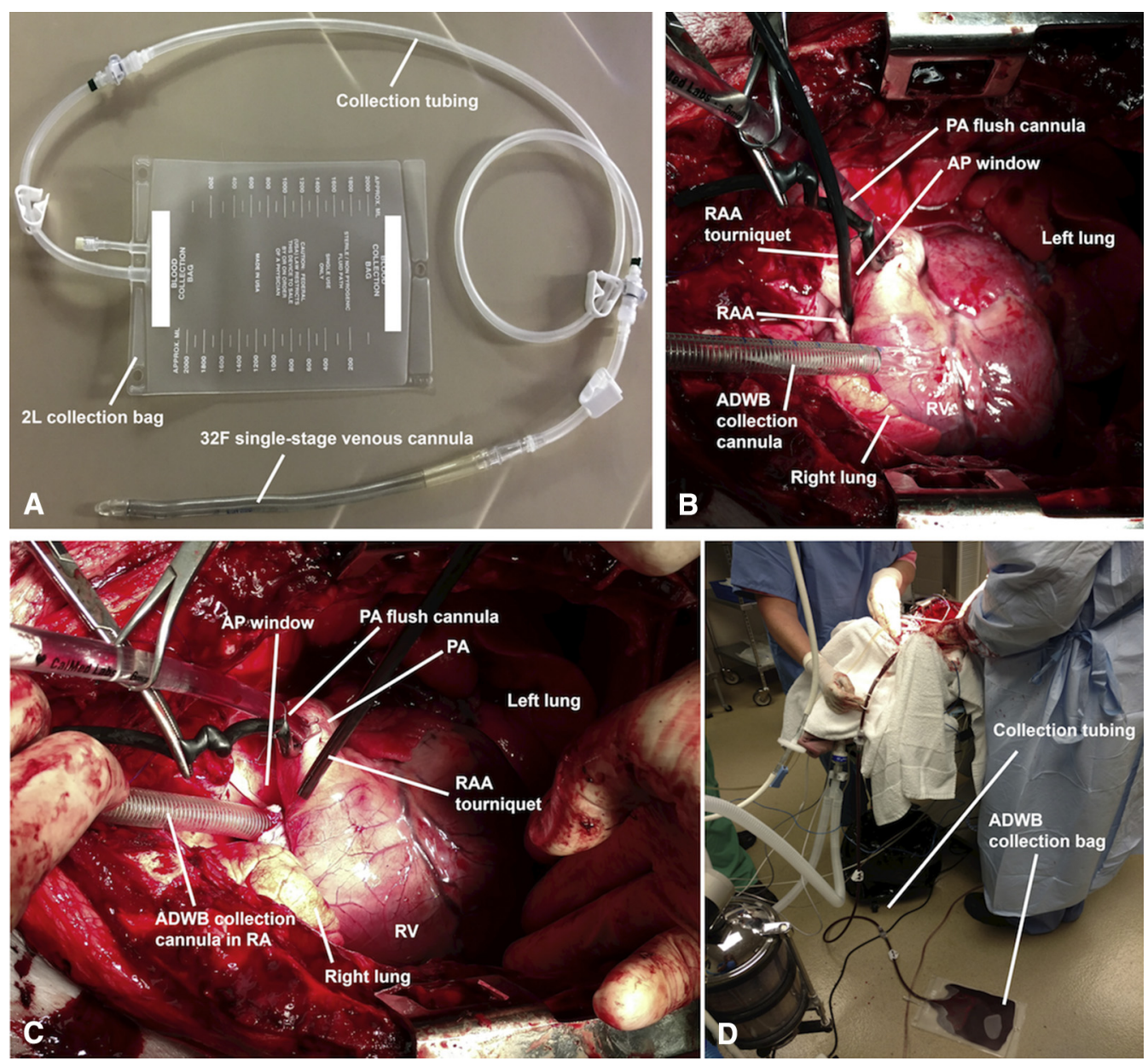

FIGURE 1. Right atrial cannulation and blood collection in a porcine model. A, Collection system. The collection system is composed of a large-volume collection bag, collection tubing, and a large single-stage venous drainage cannula. B, Initial setup. Sternotomy is performed, the heart is exposed, and both pleural spaces are entered. The aortopulmonary $(A P)$ window is developed. Antegrade flush cannulas are placed in the aortic root (not pictured) and main pulmonary artery $(P A)$. A purse-string suture is placed in the right atrial appendage $(R A A)$ and snared. The autologous donor whole blood $(A D W B)$ collection cannula is positioned cephalad and pointed caudad in preparation for right atrial cannulation, while the collection tubing and bag are passed off the field to the surgeon's left. C, Cannulation. The right atrial appendage is incised within the purse-string suture, and the cannula is introduced and directed into the inferior vena cava, while the collection tubing remains clamped. The right atrial appendage tourniquet is then secured. D, Blood collection. The collection system is unclamped, and blood is drained. Trendelenburg positioning (not pictured) may be speed this process. $R V$, Right ventricle.

the implanting team before donor crossclamp vary by institution.

\section{Preparation}

Standard median sternotomy, mediastinal dissection, and inspection of the heart and lungs are performed. The aortopulmonary window must be fully developed to facilitate crossclamping. Judicious volume administration may facilitate rapid blood collection. The use of vasopressors should be avoided immediately before collection to mitigate the risk of secondary allograft damage during EVOP.

\section{Blood-Collection Procedure}

When appropriate, full-dose heparin should be administered and allowed to circulate. Abdominal cannulation should be performed before blood collection. Standard aortic root and pulmonary artery cannulas should be placed to facilitate rapid transition to crossclamping and antegrade flush once blood collection is complete. Necessary supplies are listed in Table 1. Our preferred blood-collection system consists of a $32 \mathrm{~F}$ single-stage venous drainage cannula, standard tubing, and a 2-L collection bag (TransMedics, Inc, Andover, Mass). A right atrial (RA) purse-string stitch (3-0 or 4-0 polypropylene or braided polyester) is placed and then snared with a standard tourniquet. The RA is then cannulated through the purse-string suture to a depth of approximately $10 \mathrm{~cm}$, taking care to avoid injury to the hepatic veins. The collection system should be clamped during cannulation. The tourniquet is then secured, and the collection bag is passed off the field. 
The ABCs of Autologous Blood Collection for Ex Vivo Organ Preservation

John R Spratt, MD, MA, ${ }^{1}$ Lars M. Mattison, BS, ${ }^{1,2}$ Paul A. Iaizzo, $\mathrm{PhD}$, FHRS, ${ }^{1,2}$ and Gabriel Loor, MD ${ }^{3}$

1. Department of Surgery, University of Minnesota, Minneapolis, MN 2. Department of Biomedical Engineering, University of Minnesota, Minneapolis, MN 3. Division of Cardiothoracic Transplantation and Circulatory Support, Michael E DeBakey Department of Surgery, Baylor St. Luke's Medical Center, Houston, TX

Journal of Thoracic and Cardiovascular Surgery

Surgical Technique

June 2017

Contact: sprat020@umn.edu

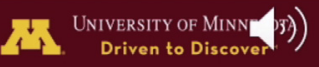

VIDEO 1. Narrated presentation describing the background and technical details of large-volume autologous donor whole blood collection. EVOP, Ex vivo organ preservation; $A D W B$, autologous donor whole blood; $R B C s$, red blood cells; $p R B C s$, packed red blood cells; $O R$, operating room; $O P O$, organ procurement organization; $P A$, pulmonary artery; $A P$, aortopulmonary; $R A A$, right atrial appendage; $R V$, right ventricle; $R A$, right atrium; $D C D$, donation after cardiac death. Video available at: http://www. jtcvsonline.org/article/S0022-5223(17)31797-X/fulltext.

The donor should be placed head down, and the drainage cannula unclamped. Drainage should be rapid ( $<90$ seconds) and continued until the necessary volume has been collected (usually approximately $1.5 \mathrm{~L}$ ). The RA appendage is then decannulated, and the collection system passed off the field. Standard procurement follows. Hypotension during blood collection is common, but any attendant insult is mitigated by expeditious collection, decannulation, crossclamping, and flush. The process is summarized in Figure 1 and Table 1.

\section{Blood Collection From Donation After Cardiac Death Donors}

After rapid sternotomy and pericardiotomy, the RA appendage can be cannulated through a stab incision with or without a purse-string suture, depending on the scenario, for immediate blood collection. This maneuver should take priority over the pulmonary artery flush, but both may occur simultaneously if 2 team members are available. Antegrade flush and procurement follow blood collection. Trendelenburg positioning facilitates rapid drainage in both scenarios.

\section{Limitations}

Adequate blood collection for EVOP is important, but the primary consideration remains the integrity of donor organs intended for transplant. RA cannulation carries the potential for hepatic vein injury or damage to the RA appendage or free wall. Blood collection should be rapid to minimize hypotensive insult, but the likelihood of significant organ injury during a short period is low. Any volume administration must be balanced against EVOP manufacturer perfusate hematocrit recommendations (generally between $15 \%$ and $30 \%$ ). Preparation should be made for standard cold preservation if failed or aborted blood collection precludes EVOP.

\section{DISCUSSION}

We report a straightforward technique for ADWB collection that can be performed by any experienced thoracic organ procurement surgeon. As ADWB collection during organ procurement gains wider acceptance, proactive communication with the multidisciplinary procurement team is critical. RA and hepatic vein injuries must be avoided. As EVOP technologies proliferate, ADWB will likely become common in organ preservation, rather than waste material discarded during procurement.

The authors acknowledge Srinath Chinnakotla, MD, for assistance with development of this protocol and Natalie Kerns, PAC, for technical assistance.

\section{References}

1. Cypel M, Yeung JC, Liu M, Anraku M, Chen F, Karolak W, et al. Normothermic ex vivo lung perfusion in clinical lung transplantation. N Engl J Med. 2011;364: 1431-40.

2. Koerner MM, Ghodsizad A, Schulz U, El Banayosy A, Koerfer R, Tenderich G. Normothermic ex vivo allograft blood perfusion in clinical heart transplantation. Heart Surg Forum. 2014;17:141.

3. Barbas AS, Goldaracena N, Dib MJ, Selzner M. Ex-vivo liver perfusion for organ preservation: recent advances in the field. Transplant Rev. 2016;30: 154-60.

4. Loor G, Howard BT, Spratt JR, Mattison LM, Panoskaltsis-Mortari A, Brown RZ et al. Prolonged EVLP using OCS lung: cellular and acellular perfusates. Transplantation. December 22, 2016 [Epub ahead of print].

5. Spratt JR, Mattison LM, Iaizzo PA, Brown RZ, Helms H, Iles TL, et al. An experimental study of the recovery of injured porcine lungs with prolonged normothermic cellular ex vivo lung perfusion following donation after circulatory death. Transpl Int. 2017;30:932-44. 